\title{
A STUDY OF THE ETIOLOGICAL RELATIONSHIP BETWEEN PELLAGRA AND PERNICIOUS ANEMIA
}

\author{
By TOM DOUGLAS SPIES AND WARREN PAYNE
}

(From the H. K. Cushing Laboratory of Experimental Medicine in the Department of Medicine of Western Reserve University and the Medical Services of Lakeside Hospital and the Cleveland City Hospital, Cleveland)

(Received for publication October 15, 1932)

Pellagra and pernicious anemia are now considered by most investigators to be deficiency diseases. The iormer has been fairly well established as a disease of dietary origin $(1,2)$ and the latter as a condition secondary to the failure of secretion of an unknown constituent of gastrir juice $(3,4)$. Both diseases are characterized by remissions and relapses, and often each is associated with glossitis, pyrexia, achylia gastrica, and numerous gastro-intestinal symptoms. Postmortem examinations show that atrophy of the gastric mucosa and involvement of the central nervous system are common findings in the patients dying of pellagra or pernicious anemia. Despite all these similarities, however, clinicians have rarely observed a co-existence of these diseases.

During the past decade great advances have been made in the study of pellagra and pernicious anemia. Goldberger and his co-workers $(1,5,6)$ have demonstrated that pellagra can be prevented and oftentimes may be cured by the adequate administration of certain foods. They have also shown (7) that yeast contains large quantities of the pellagra preventative factor (vitamin G). Minot and Murphy (8) have established that adequate oral administration of liver produces a remission in pernicious anemia. Castle et al. $(3,4)$ proved that patients with pernicious anemia lack an intrinsic gastric factor, the deficiency of which causes the disease

Sharp (9) and Sturgis and Isaacs (10) were able to produce characteristic remissions of this disease by giving ventriculin, a defatted, desiccated material prepared from pigs' stomach. While studying the effect on vitamin $G$ deficiency in rats, it was observed that ventriculin prevented and cured the signs of this deficiency (11). This observation suggested some possible relationship between vitamin $G$ and the anti-anemic factor of ventriculin (12). In view of these findings it seemed worth while to determine if the gastric juice from patients with acute pellagra contained the intrinsic factor which was shown by Castle to be absent in the gastric secretion of patients with pernicious anemia. 
The following observations are presented as evidence that this intrinsic substance is present in the gastric juice of two pellagrins.

\section{MATERIALS AND METHODS}

Two classical cases of pellagra were given a diet free of vitamin G. While receiving this diet $125 \mathrm{cc}$. of gastric juice were obtained daily, for ten days, from each pellagrin. Repeated examinations showed an absence of rennin, free hydrochloric acid, and pepsinogen. The gastric juice from each patient with pellagra was incubated at $37^{\circ} \mathrm{C}$. with 200 grams of finely ground lean beef. Each mixture was then given, following Castle's method, to two typical cases of pernicious anemia (who, on two hundred grams of beef daily, had shown a failure of hemopoietic response during a ten day control period). Daily determinations of the reticulocytes, hemoglobin (Sahli), and red cell count were done on the two anemia patients.

\section{OBSERVATIONS}

The blood findings of the two cases of pernicious anemia did not change appreciably during the ten days they received the ground beef (see Figures 1 and 2). A characteristic hemopoietic response (13) occurred, however, in each individual following the ingestion of the incubated mixture of beef and gastric juice. The peak of the reticulocyte elevation occurred on the eighth day in each instance. In Case I (Figure 1) it rose to twenty-eight per cent; in Case II (Figure 2) it rose to nine per cent. The red blood cell count and hemoglobin determination showed a subsequent progressive increase in both cases. In Case II the response was less dramatic, probably because the initial red blood cell count was 2.4 million as compared with the red blood cell count of 0.9 million in Case I.

\section{DISCUSSION}

It has been shown in these experiments that the gastric juice from two cases of pellagra, with achylia gastrica, contained a substance capable of producing an anti-anemic factor when incubated with ground beef. This work is in direct support of Castle's hypothesis that pernicious anemia is primarily a disease of the stomach and is not dependent on achylia. Since completion of this work, an article by Strauss and Castle (14) has appeared and shows that the extrinsic factor of the deficiency state in pernicious anemia is found in autoclaved yeast and is probably identical with vitamin G. Goldberger et al. (7) had previously found that this same substance prevented the development of pellagra and recommended it as a specific cure for the disease. When we consider that these two groups of investigators have demonstrated that the two diseases can be cured by the same substance, then the value of our experiment in explaining the relationship of the two diseases seems 


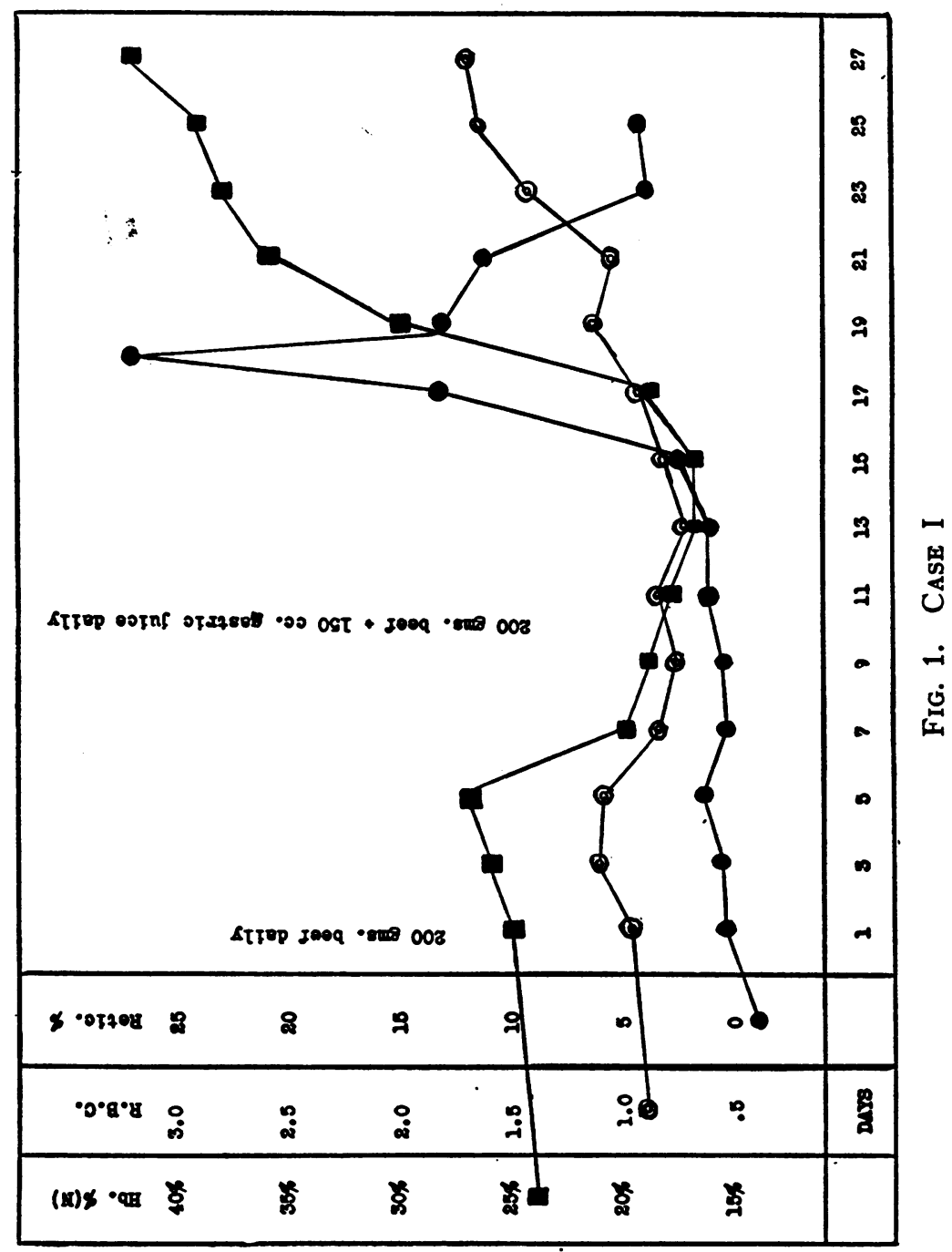




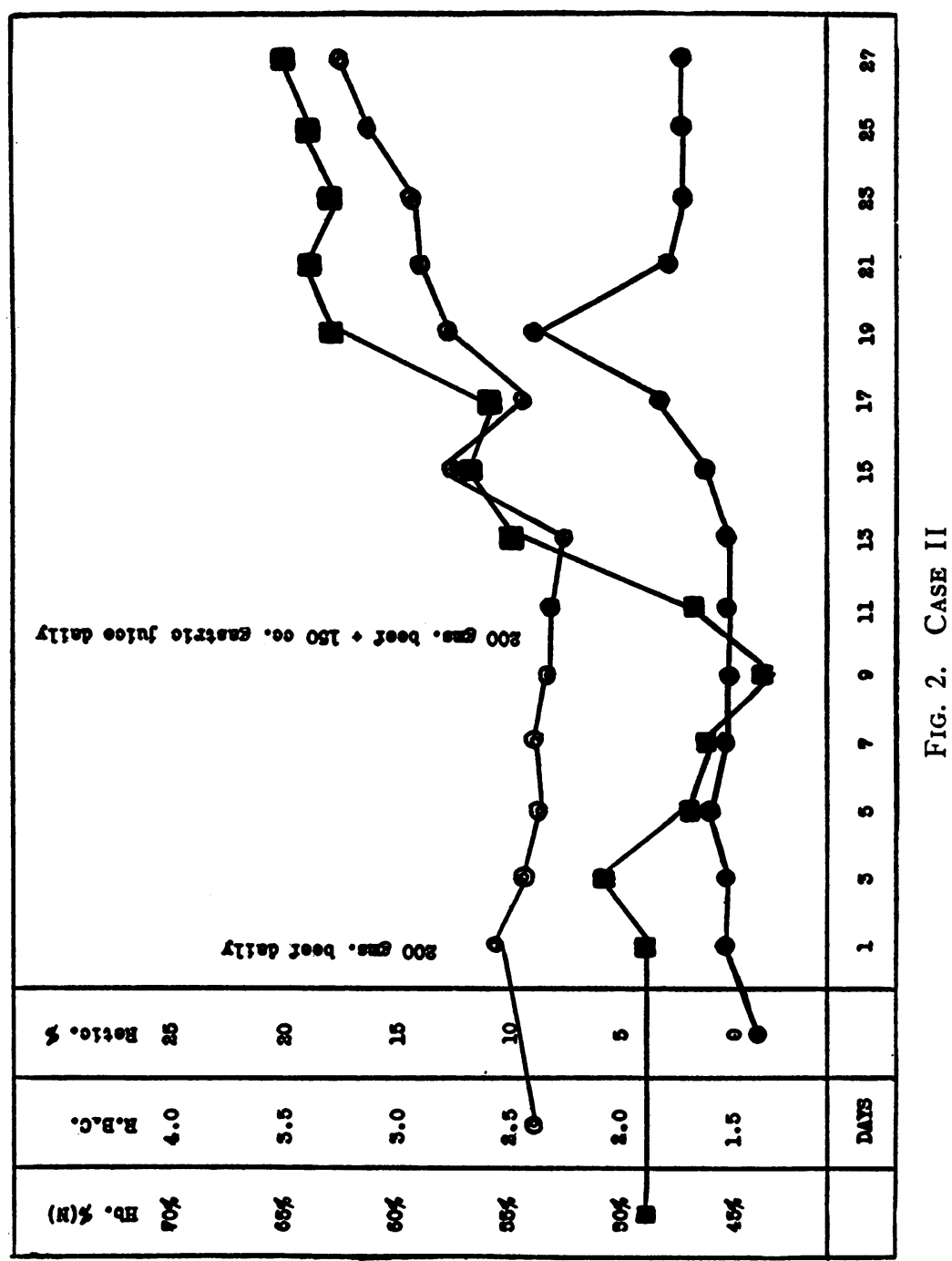


obvious. Studying the natural onset of the two conditions in the light of our experiment, it seems reasonable to state that the usual pellagrin probably acquires his disease secondary to insufficient ingestion of food and that the pernicious anemia patient probably develops his disease because of a gastric dysfunction which prevents the utilization of the extrinsic factor found in food. It follows that the rarity of co-existence of pernicious anemia and pellagra can be explained in that the former follows an inherent failure of gastric secretion of a type demonstrated to be normal in the latter.

It must be realized that our knowledge of these diseases is far from complete. While autoclaved yeast contains factors which are of therapeutic usefulness in both diseases, it does not mean that an anti-pellagric substance and the precursor of the anti-anemic factor are one and the same thing. Experimental work is proving that yeast is a mixture of many potent substances and speculation is of little value at this time as to the exact chemical nature of any of the factors.

Despite this lack of adequate chemical information concerning the external factors, the present experiment demonstrates that the gastric juice from patients with acute pellagra activates an extrinsic factor, thus producing an anti-anemic substance.

\section{SUMMARY AND CONCLUSIONS}

1. The achylic gastric juice from two cases of acute pellagra, who received a vitamin $G$ free diet, produced an anti-anemic substance when incubated with beef as shown by a characteristic hemopoietic response in two patients with pernicious anemia.

\section{BIBLIOGRAPHY}

1. Goldberger, J., Wheeler, G. A., and Sydenstricker, Edgar, U. S. Pub. Health Rep., 1920, xxxv, 648. A Study of the Relation of Diet to Pellagra Incidence.

2. Goldberger, J., and Wheeler, G. A., Bull. Hygienic Laboratory U. S., No. 120, February, 1920. The Experimental Production of Pellagra in Human Beings by Means of Diet.

3. Castle, W. B., Townsend, W. C., and Heath, C. W., Am. J. M. Sc., 1930, clxxx, 305. Observations on the Etiologic Relationship of Achylia Gastrica to Pernicious Anemia. III. The Nature of the Reaction between Normal Human Gastric Juice and Beef Muscle Leading to Clinical Improvement and Increased Blood Formation Similar to the Effect of Liver Feeding.

4. Castle, W. B., Heath, C. W., and Strauss, M. B., Am. J. M. Sc., 1931, clxxxii, 741. Observations on the Etiologic Relationship of Achylia Gastrica to Pernicious Anemia. IV. A Biologic Assay of the Gastric Secretion of Patients with Pernicious Anemia Having Free Hydrochloric Acid and That of Patients without Anemia or with Hypochromic Anemia Having No Free Hydrochloric Acid, and of the Role of Intestinal Impermeability to Hematopoietic Substances in Pernicious Anemia. 
5. Goldberger, J., and Wheeler, G. A., U. S. Pub. Health Rep., 1929, xliv, 2769. A Study of the Pellagra-Preventive Action of Canned Salmon.

6. Goldberger, J., and Wheeler, G. A., U. S. Pub. Health Rep., 1927, xlii, 2383. A Study of the Pellagra-Preventive Action of the Cowpea (Vigna sinensis) and of Commercial Wheat Germ.

7. Goldberger, J., Wheeler, G. A., Lillie, R. D., and Rogers, L. M., U. S. Pub. Health Rep., 1926, xli, 297. A Further Study of Butter, Fresh Beef and Yeast as Pellagra Preventives with Consideration of the Relation of Factor P-P of Pellagra (and Black Tongue of Dogs) to Vitamin B.

8. Minot, G. R., and Murphy, W. P., J. A. M. A., 1927, lxxxix, 759. A Diet Rich in Liver in the Treatment of Pernicious Anemia: Study of One Hundred and Five Cases.

9. Sharp, E. A., J. A. M. A., 1929, xciii, 749. An Antianemic Factor in Desiccated Stomach.

10. Sturgis, C. C., and Isaacs, R., J. A. M. A., 1929, xciii, 747. Desiccated Stomach in the Treatment of Pernicious Anemia.

11. Spies, T. D., South. Med. and Surg., 1932, xciv, 128. Pellagra: Etiology; Response to a Deficient Diet.

12. Spies, T. D., Pellagra: Response to a So-Called "Pellagra-Producing" Diet. (In press.)

13. Minot, G. R., Murphy, W. P., and Stetson, R. P., Am. J. M. Sci., 1928, clxxv, 581. The Response of the Reticulocytes to Liver Therapy, Particularly in Pernicious Anemia.

14. Strauss, M. B., and Castle, W. B., New England J. Med., 1932, ccvii, 55. The Nature of the Extrinsic Factor of the Deficiency State in Pernicious Anemia and in Related Macrocytic Anemias. Activation of Yeast Derivatives with Normal Human Gastric Juice. 